\title{
DEBRET E RUGENDAS NOS LIVROS DIDÁTICOS: ENSINO DE HISTÓRIA POR MEIO DE IMAGENS
}

\author{
Marco Antonio Alves de Oliveira ${ }^{1}$ \\ Maiara Sanches Leite ${ }^{2}$ \\ Ana Enedi Prince ${ }^{3}$
}

Resumo: Esse estudo tem como objetivo discutir o uso de imagens na compreensão de História, considerando este como um importante recurso didático e metodológico a ser utilizado na prática docente. Sendo assim, selecionamos algumas obras de Jean-Baptiste Debret e Johan Moritiz Rugendas como objetos de analise devido às importantes contribuições culturais à história, durante sua permanência no Brasil. Para a melhor compreensão desse ensaio, observamos livros didáticos e suas características, a fim de reconhecer a iconografia como parte relevante que compõe o processo de ensino de História.

Palavras-chave: História; Brasil; Imagens; Ensino; Aprendizagem.

\footnotetext{
1 História/Universidade do Vale d Paraíba, Brasil. E-mail: marcoantonio_ao@hotmail.com.

2 História/Universidade do Vale do Paraíba, Brasil. E-mail: maiarasanches12@gmail.com.

${ }^{3}$ História/Universidade do Vale do Paraíba, Brasil. E-mail: prince@univap.br.
} 